\title{
COMMENTARY
}

\section{Sodium bicarbonate to prevent cardiac surgery- associated kidney injury: the end of a dream?}

\author{
Jean-Michel Hougardy’ and Daniel De Backer* \\ See related research by Heringlake et al., http://ccforum.com/content/16/4/R156
}

\begin{abstract}
The rationale of urine alkalinization through intravenous sodium bicarbonate to prevent cardiac surgery-associated acute kidney injury relies on several pathophysiological arguments. Urine alkalinization is easily feasible in the ICU setting and is often considered to be associated with few side effects. In a previous issue of Critical Care, a retrospective study evaluates the effect of routine intravenous bicarbonate use to prevent cardiac surgery-associated acute kidney injury with cardiopulmonary bypass. This commentary discusses recent data on the use of bicarbonate to prevent cardiac surgery-associated acute kidney injury.
\end{abstract}

In a previous issue of Critical Care, Heringlake and colleagues [1] report important results of a cohort analysis of use of bicarbonate to prevent cardiac surgeryassociated acute kidney injury (CSA-AKI). Acute kidney injury (AKI) is common in hospitalized patients and is associated with increased morbidity and mortality. Cardiac surgery with cardiopulmonary bypass $(\mathrm{CPB})$ is the second leading cause of AKI in the ICU, just after sepsis [2]. CSA-AKI incidence varies widely in the literature, usually in between $3 \%$ and $50 \%$ of patients undergoing $\mathrm{CPB}[3,4]$. Its occurrence depends on several procedure-related (type of cardiac surgery, duration of aortic cross-clamping, CPB time) and patient-dependent factors (age, chronic kidney disease, low left ventricular ejection fraction, peripheral vascular disease, diabetes). The incidence of CSA-AKI is only $2.3 \%$ in isolated coronary artery bypass graft procedures in patients without comorbidities but its incidence rises up to $15 \%$ in patients also with chronic kidney disease [5]. Due to its

\footnotetext{
*Correspondence: ddebacke@ulb.ac.be

2Department of Intensive Care, Erasme University Hospital, Université Libre de Bruxelles, B-1070 Brussels, Belgium

Full list of author information is available at the end of the article
}

significant incidence and influence on resource utilization and potentially on mortality, the prevention and/or treatment of CSA-AKI is a relevant issue.

Pathophysiology of CPB-AKI is complex, mainly relying on hemodynamic and inflammatory disturbances $[3,6]$. CPB is associated with ischemia-reperfusion injury but also with significant release of free hemoglobin and iron. Nevertheless, the respective importance of the different pathophysiological processes in CSA-AKI remains unclear. In addition, nephrotoxic drugs, anemia and blood transfusions may further exacerbate CSA-AKI.

Experimental data have shown that higher tubular $\mathrm{pH}$ could be protective in the presence of hemoglobinuria or myoglobinuria [7], especially through inhibition of hydroxyl radical generation and lipid peroxidation, which could be central in AKI [8-10]. In analogy with the beneficial effects of urine alkalinization after rhabdomyolysis [11], urine alkalinization after intravenous bicarbonate was thought to prevent CSA-AKI. In a pilot randomized study including 100 patients submitted to cardiac surgery with $\mathrm{CPB}$, perioperative bicarbonate administration decreased the proportion of patients experiencing an increase in creatinine from 52 to $32 \%(P=0.043)$ [12]. In addition, bicarbonate blunted the increase in biomarkers of AKI.

However, bicarbonate may not be the right agent to prevent CSA-AKI. Indeed, bicarbonate failed to prevent experimental ischemia-induced AKI [13]. It also fails to prevent contrast-induced nephropathy $[14,15]$, another condition where ischemia is thought to occur. Hence, confirmatory trials in CSA-AKI are warranted.

In this issue, Heringlake and colleagues [1] reported the absence of superiority of intravenous bicarbonate for the prevention of CSA-AKI in comparison to saline. The authors retrospectively compared a cohort of 280 patients who received $4 \mathrm{mmol}$ sodium bicarbonate per kilogram to a control cohort. The proportion of patients experiencing an increase in creatinine by $25 \%$ was similar in both groups ( $41.1 \%$ in bicarbonate versus $32.9 \%$ in control, $P=$ not significant). Strikingly, this study is in contrast to the pilot study by Haase and colleagues [12], even though intravenous bicarbonate was used in a 
comparable manner and similarly alkalinized blood $\mathrm{pH}$ in both studies.

Several factors could explain the differences between these two studies. First, the Haase study included prospectively selected patients with significant risk for CSA-AKI while the Heringlake study was retrospective and included nearly all patients undergoing cardiacsurgery with $\mathrm{CPB}$ in their center. As mentioned above, heterogeneity in patient populations is an important factor determining the risk for CSA-AKI. This may be explained by inclusion in the latter trial of $38 \%$ of patients undergoing isolated coronary artery bypass graft, which shows the lowest CSA-AKI risk. This limits of course the chances to see a beneficial impact of bicarbonate. Nevertheless the incidence of CSA-AKI was still close to $33 \%$, which is not negligible. Second, the Heringlake trial had the advantage of including almost all patients admitted to their center, which increases external validity of the results. Interestingly, bicarbonate may also be associated with detrimental effects. Mean arterial blood pressure was lower after induction of anesthesia, and patients required more fluids and vasopressors and spent more time in a high dependency unit [1]. Previous work has already drawn attention to the side effects of bicarbonate: overcorrection of acidosis significantly increased mortality [16] and several experiments have reported that intracellular alkalinization hastened cell death after anoxia, stimulated superoxide formation, enhanced proinflammatory cytokine release and apoptosis, and increased blood lactate and ketone bodies [17]. Therefore, use of bicarbonate for CSA-AKI prevention could be a double-edged sword where risk may overwhelm benefits if applied in a non-selected patient population.

These contradictory data raise questions about bicarbonate efficiency for CSA-AKI prevention. From the data published, it seems that bicarbonate is useless in an unselected population [1]. Bicarbonate may still be effective in patients at high risk of CSA-AKI and results of confirmatory trials are needed. Nevertheless, preliminary results of a randomized trial in 427 patients at high risk of CSA-AKI reported a similar incidence of CSA-AKI of $45 \%$ in the bicarbonate group and $44 \%$ in the saline group [18]. The debate is therefore still open but data do not actually support routine use of bicarbonate for CSA-AKI prevention.

\section{Abbreviations}

AKI, acute kidney injury; CPB, cardiopulmonary bypass; CSA-AKI, cardiac surgery-associated acute kidney injury.

\section{Competing interests}

The authors declare that they have no competing interests.

\section{Authors' contributions}

The authors equally contributed to this work.

\section{Author details}

'Department of Nephrology and Erasme University Hospital, Université Libre de Bruxelles, B-1070 Brussels, Belgium. ²Department of Intensive Care, Erasme University Hospital, Université Libre de Bruxelles, B-1070 Brussels, Belgium.

\section{Published: 12 December 2012}

\section{References}

1. Heringlake M, Heinze H, Schubert M, Novak Y, Guder J, Kleinebrahm M, Paarmann H, Hanke T, Schon J: A perioperative infusion of sodium bicarbonate does not improve renal function in cardiac surgery patients: a prospective observational cohort study. Crit Care 2012, 16:R156.

2. Uchino S, Kellum JA, Bellomo R, Doig GS, Morimatsu H, Morgera S, Schetz M, Tan I, Bouman C, Macedo E, Gibney N, Tolwani A, Ronco C: Acute renal failure in critically ill patients: a multinational, multicenter study. JAMA 2005, 294:813-818

3. Haase M, Bellomo R, Haase-Fielitz A: Novel biomarkers, oxidative stress, and the role of labile iron toxicity in cardiopulmonary bypass-associated acute kidney injury. J Am Coll Cardiol 2010, 55:2024-2033.

4. Weisberg LS: Sodium bicarbonate for renal protection after heart surgery: let's wait and see. Crit Care Med 2009, 37:333-334.

5. Shahian DM, O'Brien SM, Filardo G, Ferraris VA, Haan CK, Rich JB, Normand SL, DeLong ER, Shewan CM, Dokholyan RS, Peterson ED, Edwards FH, Anderson RP: The Society of Thoracic Surgeons 2008 cardiac surgery risk models: part 1 - coronary artery bypass grafting surgery. Ann Thorac Surg 2009, 88:S2-22.

6. Haase M, Haase-Fielitz A, Bellomo R: Cardiopulmonary bypass, hemolysis, free iron, acute kidney injury and the impact of bicarbonate. Contrib Nephrol 2010, 165:28-32.

7. Atkins JL: Effect of sodium bicarbonate preloading on ischemic renal failure. Nephron 1986, 44:70-74

8. Caulfield JL, Singh SP, Wishnok JS, Deen WM, Tannenbaum SR: Bicarbonate inhibits $\mathrm{N}$-nitrosation in oxygenated nitric oxide solutions. J Biol Chem 1996, 271:25859-25863.

9. Hingorani S, Molitoris BA, Himmelfarb J: Ironing out the pathogenesis of acute kidney injury. Am J Kidney Dis 2009, 53:569-571.

10. Bonventre JV, Weinberg JM: Recent advances in the pathophysiology of ischemic acute renal failure. J Am Soc Nephrol 2003, 14:2199-2210.

11. Bosch X, Poch E, Grau JM: Rhabdomyolysis and acute kidney injury. N Eng/f Med 2009, 361:62-72

12. Haase M, Haase-Fielitz A, Bellomo R, Devarajan P, Story D, Matalanis G, Reade MC, Bagshaw SM, Seevanayagam N, Seevanayagam S, Doolan L, Buxton B, Dragun D: Sodium bicarbonate to prevent increases in serum creatinine after cardiac surgery: a pilot double-blind, randomized controlled trial. Crit Care Med 2009, 37:39-47.

13. Sporer H, Lang F, Oberleithner H, Greger R, Deetjen P: Inefficacy of bicarbonate infusions on the course of postischaemic acute renal failure in the rat. Eur J Clin Invest 1981, 11:311-315.

14. Baber U, Mehran R: Prevention of contrast-induced AKI - the ongoing saga. Nat Rev Nephrol 2012, 8:260-261

15. Zoungas S, Ninomiya T, Huxley R, Cass A, Jardine M, Gallagher M, Patel A, Vasheghani-Farahani A, Sadigh G, Perkovic V: Systematic review: sodium bicarbonate treatment regimens for the prevention of contrast-induced nephropathy. Ann Intern Med 2009, 151:631-638.

16. Anderson LE, Henrich WL: Alkalemia-associated morbidity and mortality in medical and surgical patients. South Med J 1987, 80:729-733.

17. Sabatini S, Kurtzman NA: Bicarbonate therapy in severe metabolic acidosis. J Am Soc Nephrol 2009, 20:692-695

18. McGuinness P, Parke RL, Bellomo R, van Haren FM: Sodium bicarbonate to reduce cardiac surgery associated acute kidney injury: A phase II multicentre, double-blind, randomized clinical trial [abstract]. Am J Respir Crit Care Med 2012, 185:A6857.

doi:10.1186/cc11837

Cite this article as: Hougardy JM, De Backer D: Sodium bicarbonate to prevent cardiac surgery-associated kidney injury: the end of a dream? Critical Care 2012, 16:186. 